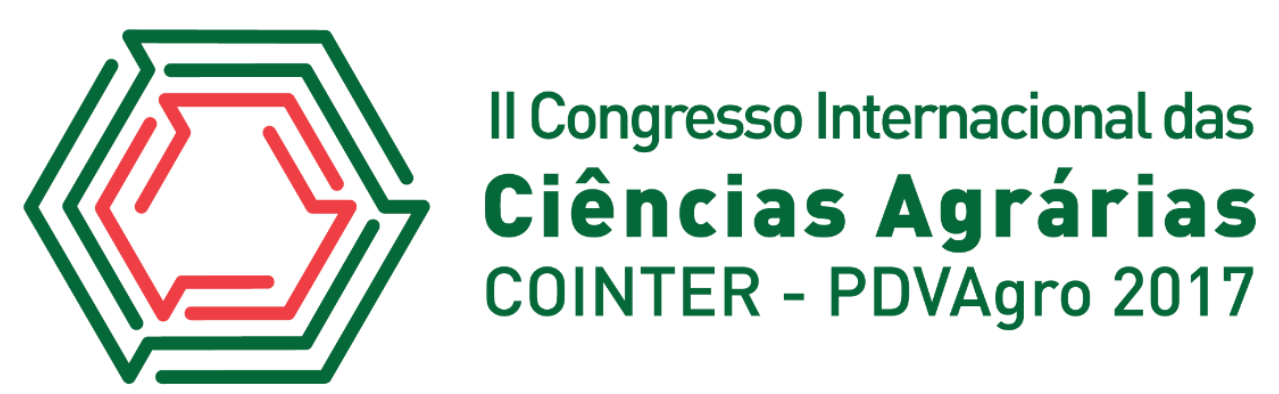

\title{
TEORES DE FÓSFORO EM DIFERENTES CULTIVOS EM LATOSSOLO AMARELO NO MUNICÍPIO DE ABAETETUBA-PA
}

\author{
Apresentação: Pôster \\ Samara Thais Da Costa Pinheiro ${ }^{1}$; Fiama Kelly Melo Nunes²; Gabriel Anderson Martins Dos \\ Santos $^{3}$; João Carlos Dos Santos Duarte ${ }^{4}$; Eder Silva de Oliveira ${ }^{5}$
}

\section{Introdução}

Os solos paraenses são considerados pobres em P, porém essa afirmativa não é totalmente verdadeira, uma vez que o P contido no material de origem do solo encontra-se totalmente na forma mineral, com predomínio dos fosfatos de Ca (RHEINHEIMER; ANGHINONI, 2001), com o processo de intemperização o fósforo torna-se disponível na fração da solução do solo e assim a atividade de $\mathrm{Al}$ e Fe é aumentada e, por conseguinte ocorrerá a transformação dos minerais de argila do tipo 2:1 em minerais do tipo 1:1, e estes por sua vez em óxidos. Os Latossolos da região amazônica, de uma maneira geral, pelas suas características de solos intemperizados e de baixa fertilidade podem ser limitantes no desenvolvimento das culturas (BRITO, 2004).

O fósforo é considerado um macronutriente, ou seja, nutriente que é exigido em quantidades maiores pelas plantas. Para as plantas esse macronutriente é necessário para fotossíntese, respiração, transferência de genes e em processos que envolvem transferência de energia (STAUFFER; SULEWSKI, 2003). Este elemento estimula o crescimento das raízes, apressa a maturação, estimula o florescimento e ajuda na formação de sementes. (MALAVOLTA, 1989).

\section{Fundamentação Teórica}

O presente trabalho baseou-se na avaliação de Fósforo em três diferentes cultivos, são eles: pastagem, açaí (Euterpe oleracea Mart.) e milho (Zea mays). Inúmeros fatores podem interferir na

\footnotetext{
${ }^{1}$ Engenharia Florestal, Universidade Federal Rural Da Amazônia, samarathaiscosta@gmail.com

${ }^{2}$ Engenharia Florestal, Universidade Federal Rural Da Amazônia, fiamamelo10@outlook.coml

${ }^{3}$ Agronomia, Universidade Federal Rural Da Amazônia, gabrmartins20@gmail.com

${ }^{4}$ Agronomia, Universidade Federal Rural Da Amazônia, duarte.joaocarlos17@gmail.com

${ }^{5}$ Doutorando, Universidade Federal Rural Da Amazônia, ederso@uepa.br
} 
analise deste nutriente, pois este elemento tem grande atração por coloides com $\mathrm{Al}$ e $\mathrm{Fe}$, o que o torna indisponível para as plantas. Dentre os minerais que possuem alto poder de adsorção, processo de fixação do P ao coloide, está Hematita, Goethita e Gibbsita, cuja incidência nos solos paraenses é elevada. Como consequência, as plantas cultivadas em solos tropicais ácidos, ricos em ferro e alumínio, não conseguem frequentemente aproveitar mais do que $10 \%$ do fósforo total aplicado (BRITO, 2004).

A disponibilidade de fósforo é afetada pela acidez ativa do solo- $\mathrm{pH}$; teor de matéria orgânica; fator intensidade- $\mathrm{P}$ disponível na solução do solo, que é a fração que a planta absorve. $\mathrm{O}$ fósforo move-se no solo por difusão e seu movimento lento no solo ocorre principalmente em função da sua elevada reatividade e por estar comumente em teor inferior ao adequado para diversas culturas, podendo apresentar indisponibilidade à planta (BASTOS, 2008).

\section{Metodologia}

A área objeto de estudo deste trabalho foi a Fazenda Bela Vista, com cerca de 480 ha, da qual a sede está localizada na latitude 154’30,64”S e longitude 4853'18,54”O, situada na região sul do município de Abaetetuba, Estado do Pará. A principal via de acesso à Fazenda é a PA-151.

O tipo de solo predominante na região é o Latossolo Amarelo distrófico. A coleta de solo para análise foi feita no primeiro e terceiro finais de semanas do mês maio de 2017. As amostras coletadas foram de 3 áreas: primeira área com pastagem, segunda área contendo plantações de açaí e a terceira área contendo plantações de milho. As profundidades coletadas foram de 0-20 cm e de 20-40 cm, para as três áreas, a partir de então foram divididos em 6 Tratamentos, com 4 repetições cada, são eles: T1- Pastagem de 0-20 cm; T2- Pastagem de 20-40 cm; T3- Açaí de 0-20 cm; T4Açaí de 20-40 cm; T5- Milho de 0-20 cm e T6- Milho de 20-40 cm. Posteriormente, as coletas foram analisadas no Laboratório de Química do Solo da Universidade Federal Rural Da AmazôniaUFRA.

O solo foi seco e subsequentemente peneirado até tornar-se Terra Fina Seca ao Ar- TFSA. Prosseguindo, foram pesados $10 \mathrm{ml}$ de TFSA e adicionados $100 \mathrm{ml}$ da solução extratora de Mehlich 1, composta de $\mathrm{HCl}$ e $\mathrm{H}_{2} \mathrm{SO}_{4}$, as soluções foram agitadas por cerca de 30 minutos e depois foram colocadas para decantar no período de uma noite. Na manhã seguinte formou-se uma solução contendo $5 \mathrm{ml}$ do extrato e $5 \mathrm{ml}$ de solução ácida de molibdato de amônio diluída. A solução 
descansou por 1 hora e posteriormente foi feita a leitura de $\mathrm{P}$ utilizando o espectrofotômetro.

O cálculo de fósforo disponível foi feita através da expressão:

$$
\mathrm{mg} \text { de } \mathrm{P} / \mathrm{dm}^{3} \text { de TFSA }=(\mathrm{La}-\mathrm{b}) \times 10
$$

a

Onde:

La: Leitura da Prova em Branco, solução contendo todas as soluções com exceção da solução do extrato;

a e b: são coeficientes obtidos grafando-se os valores de concentrações de fósforo dos padrões no eixo das abscissas e as referentes leituras no eixo das ordenadas.

\section{Resultados e Discussões}

Os dados demonstrados na figura 1 resultaram em valores significativos entre os tratamentos. O que de fato torna-se relevante já que todos os tratamentos pertencem ao mesmo tipo de solo, o Latossolo Amarelo distrófico, cuja principal característica é a elevada quantidade de óxidos de Alumínio e Ferro, o solo é o fator que correlaciona os tratamentos. Porém, houve uma diferença nas médias do T3 e T4, apesar de pertencerem ao mesmo cultivo.

Figura 1: Teste de Tukey para fósforo em diferentes cultivos. Fonte: Própria.

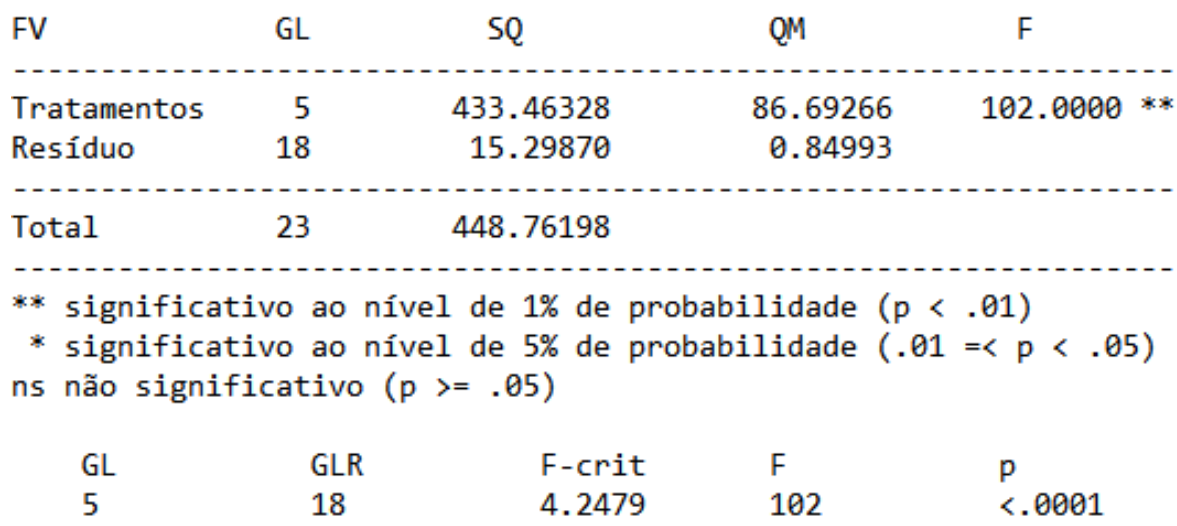

Os Tratamentos 3 e 4 pertencem ao mesmo cultivo, o açaí. Todavia, houve diferença significativa não apenas entres os cultivos, mas também entre o T4 e os demais tratamentos. A explicação leva em consideração o tipo de raiz que o açaí tem, além da mobilidade do P no solo. De acordo com Oliveira (2012), o sistema radicular é do tipo fasciculado, relativamente denso, com raízes emergindo do estipe da planta adulta até a altura de $40 \mathrm{~cm}$ acima da superfície do solo. 
Devido às raízes não serem profundas, a cultura não atingiu a região do solo em que se encontraram quantidades maiores de $\mathrm{P}$, região essa pertencente ao T4, cuja profundidade é de 20-40 $\mathrm{cm}$. Outro fator que explica a diferença é a mobilidade de P-como ele é pouco móvel no solo, há uma grande dificuldade desse nutriente em deslocar-se para outras profundidades-, além da adubação fosfatada aplicada na área do cultivo. Como houve adubação, a cultura absorveu pelas raízes o nutriente que estava na profundidade mais superficial e o restante moveu-se para maiores profundidades, por ação da gravidade. Na figura 2 os números 1, 2, 3, 4,5 e 6 referem-se respectivamente a T1, T2, T3, T4, T5 e T6. Nos outros tratamentos as quantidades de fósforos encontradas tiveram valores aproximados.

Figura 2: Médias de Tratamentos de fósforo em diferentes profundidades e cultivos. Fonte: própria.

\begin{tabular}{cr} 
Médias de tratamento \\
\hline 1 & $3.07000 \mathrm{~b}$ \\
2 & $2.81750 \mathrm{~b}$ \\
3 & $3.72250 \mathrm{~b}$ \\
4 & $14.43250 \mathrm{a}$ \\
5 & $3.33000 \mathrm{~b}$ \\
6 & $2.45250 \mathrm{~b}$
\end{tabular}

Legenda: As médias seguidas pela mesma letra não diferem estatisticamente entre si. Foi aplicado o Teste de Tukey ao nível de $5 \%$ de probabilidade.

Os dados encontrados na análise química de fósforo no solo teve média de aproximadamente $2.06 \mathrm{mg} / \mathrm{dm}^{3}$, resultado semelhante encontrado nas analises de VELOSO (2015), cujo valor encontrado para $\mathrm{P}$ foi de $2.0 \mathrm{mg} / \mathrm{dm}^{3}$.

\section{Conclusões}

Os resultados mostraram que as quantidades de fósforo no solo do tipo Latossolo Amarelo distrófico encontrado no município de Abaetetuba, em diferentes cultivos é baixa, somado a isso está à baixa mobilidade do nutriente no solo, o que torna ainda mais dificultoso a disponibilidade na solução do solo. Fatores adotados que poderiam auxiliar em maior disponibilidade seriam: a calagem- que neutralizaria o alumínio trocável no solo, diminuindo assim a adsorção aos minerais como Gibbsita-, a elevação da quantidade de matéria orgânica, pois a mesma disponibiliza ao solo o nutriente, além de recobrir os sítios de hidróxidos de alumínio tornando o $\mathrm{P}$ mais disponível na solução. 


\section{Referências}

BASTOS, Adelmo L. et al. Influência de doses de fósforo no fluxo difusivo em solos de Alagoas. Revista Brasileira de Engenharia Agrícola e Ambiental, v. 12, n. 2, p. 136-142, 2008.

BRITO, J. do S. et al. Conteúdo de nitrogênio, fósforo e enxofre em plantas de açaizeiro (Euterpe oleracea Mart.). In: Embrapa Amazônia Oriental-Artigo em anais de congresso (ALICE). In: REUNIÃO BRASILEIRA DE FERTILIDADE DO SOLO E NUTRIÇÃO DE PLANTAS, 26.; REUNIÃO BRASILEIRA SOBRE MICORRIZAS, 10.; SIMPÓSIO BRASILEIRO DE MICROBIOLOGIA DO SOLO, 5., 2004, Lages. Fertbio 2004:[anais]. Lages: SBCS, 2004.

OLIVEIRA, Maria do Socorro Padilha de et al. Cultivo do açaizeiro para produção de frutos. 2002.

DOS SANTOS RHEINHEIMER, Danilo; ANGHINONI, Ibanor. Distribuição do fósforo inorgânico em sistemas de manejo de solo. Pesq. agropec. bras., Brasília, v. 36, n. 1, p. 151-160, 2001.

MALAVOLTA, E. ABC da adubação. São Paulo: Ceres, 1989.304p.

SILVA, F. de A. S. e.; AZEVEDO, C. A. V. de. The Assistat Software Version 7.7 and its use in the analysis of experimental data. Afr. J. Agric. Res, v.11, n.39, p.3733-3740, 2016. DOI: $10.5897 / A J A R 2016.11522$

STAUFFER, M. D.; SULEWSKI, G. Fósforo: nutriente essencial para a vida. Informações Agronômicas, Piracicaba, n.102, p.1-2, 2003.

VELOSO, Carlos Alberto Costa; SILVA, Arystides Resende; SALES, Agust. Manejo da adubação NPK na formação do açaizeiro em latossolo amarelo do Nordeste paraense. Embrapa Amazônia Oriental-Artigo em periódico indexado (ALICE), 2015. 